\title{
Adaptive Structures and Biomimetic Robots - A Perspective
}

\author{
A. Concilio ${ }^{1, *}$, I. Dimino ${ }^{1}$, S. Ameduri ${ }^{1}$ and R. Pecora ${ }^{2}$ \\ ${ }^{1}$ CIRA, The Italian Aerospace Research Centre, Adaptive Structures Division, Capua (CE), Italy \\ ${ }^{2}$ University of Naples "Federico II", Department of Industrial Engineering-Aerospace Division, Napoli, Italy
}

\begin{abstract}
This paper gives an overview of some recent full-scale demonstrations of morphing devices capable of providing innovative capabilities to general systems in changing shape and improving performance significantly during operations. In aeronautics, large progress has been observed over the last few years, meaning that this technology is rapidly transitioning from laboratory scale to high TRL demonstrators. The most advanced concepts already proved to withstand loads with minimal deformation while having the capability to change their geometry to attain additional benefits with respect to their original mission. In the same way, robotics has become one of the most prominent technological trends of the current century. The rapid increase in their use and development has significantly changed our society by gradually replacing a large share of human jobs. Such an evolution is also rapidly accelerating, as technological advances in automation, engineering, artificial intelligence, and machine learning converge. Since both domains involve the integration of actuators, sensors and controllers and face integrity challenges in harsh environments, they may be seen somehow related and probably share a common future. In this article, the authors propose an original view of a possible future scenario that is likely to consider a unique development path for research on adaptive structures and robotics.
\end{abstract}

Keywords: Morphing wing, Adaptive wing, Robotics, Futuristic vision.

\section{RECENT DEVELOPMENTS OF ADAPTIVE STRUCTURES FOR AERONAUTICAL APPLICATIONS}

Recently, a certain attention of the Aerospace Engineering world has moved towards smart or adaptive structures; in particular, towards systems able to bear loads while deforming their shape or changing their geometrical configuration (morphing). Many issues must still be faced and completely overcome in order to practically implement such a kind of architectures, as illustrated in some representative textbooks [1-3]. The main of them, however, stands just in the foreword: creating structures that shall withstand external forces with minimal deformation while being able to change their outline a contradictory characteristic that is sometimes referred to as "the paradox of smart (or adaptive) structures". Indeed, this kind of aspect is not brand new. General aircraft have special devices for maneuver (as flaps and slats) or cruise control (as ailerons), which make possible to "change the wing geometry" to face different needs at different speeds and environmental conditions (ascent, descent, turn and so on). Either, some movable devices are already implemented to alleviate gust effects. Among many other aspects that would require specific attention, what is new in the proposed layouts is the perfect integration of active components

\footnotetext{
*Address correspondence to this author at the CIRA, The Italian Aerospace Research Centre, Adaptive Structures Division, Capua (CE), Italy; Tel: +39 0823623 342; E-mail: A.Concilio@cira.it
}

(actuator and sensor systems) and adaptive skeleton (deformable structure), sometimes shrouded by a highly-deformable skin. The result is a wing that can change its shape without giving any evidence of the internal apparatus that allows this capacity.

At the time being, the most advanced studies confined the movement to essential features. For instance, some devices proposed three degrees of freedom schemes along the chord, usually composed with increasing complexity along the span to enable articulated camber curvature, almost resembling a wide and complex finger or even almost a continuous hand (kinematic systems). It is possible to find in literature more complex elaborations of that concept, enabling translation and further combined movements, but the basic layout remains. Something different can be found in the compliant systems, where embedded kinematics aims at deforming a continuous elastic structure, namely generating a larger number of degrees of freedom. However, even in that case, the implemented architecture produces limited supplementary mobility. Representative examples of those architectures are reported in Figure 1. They refer respectively to an adaptive trailing edge, designed and realized by a team led by the University of Napoli within the Clean Sky 1 European Program, [4], and a compliant leading edge, designed and realized by a team led by the DLR within the SARISTU project, [5].

Within these boundaries, results are yet incredibly interesting. Projects like the already cited SARISTU in 


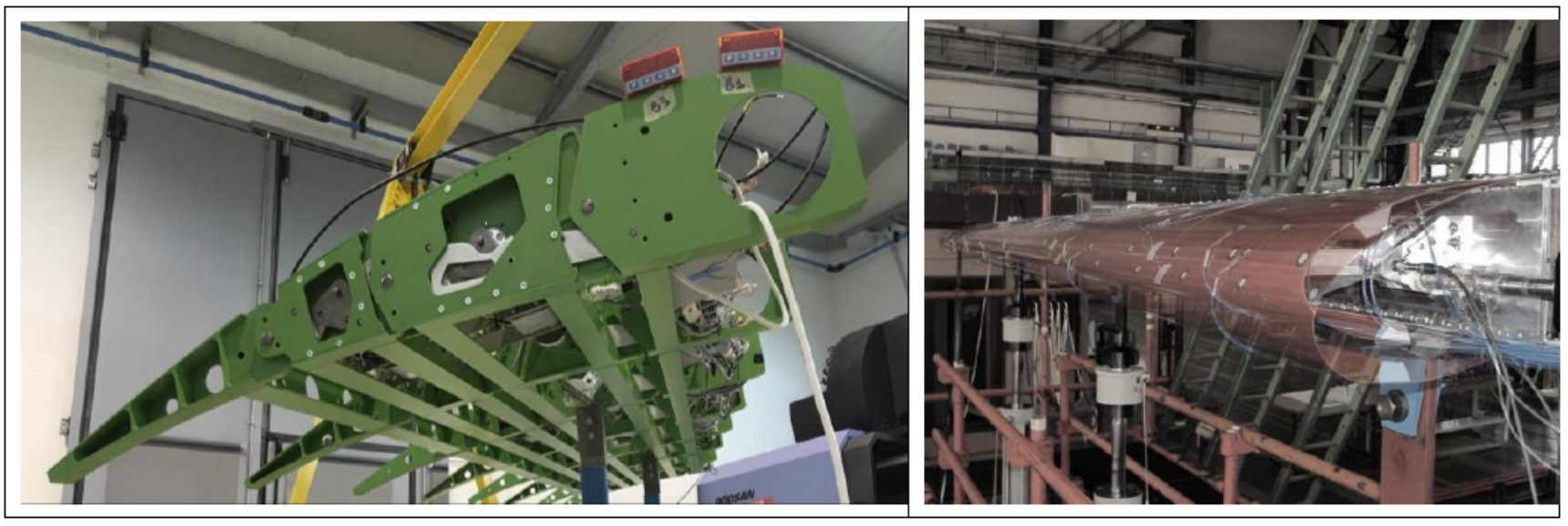

Figure 1: Large scale morphing wing devices: (left) morphing flap kinematics; (right) conformal droop nose, [4, 5].

Europe, $[2,5,6]$, or Adaptive Compliant Trailing Edge in USA, [7], proposed full-size wings integrated with multiple actuation systems and distributed sensor networks. In detail, SARISTU presented a $5.5 \mathrm{~m}$ span wing equipped with an adaptive leading edge (the fore part of the wing), an adaptive trailing edge (the aft part) and a winglet (the wing tip), capable of giving the basic structure incredible shape variations. It was tested in Wind Tunnel up to M 0.3 (around $370 \mathrm{~km} / \mathrm{h}$ at sea level), after having been sized for M 0.75 (a common velocity for an airline airplane), Figure 2.

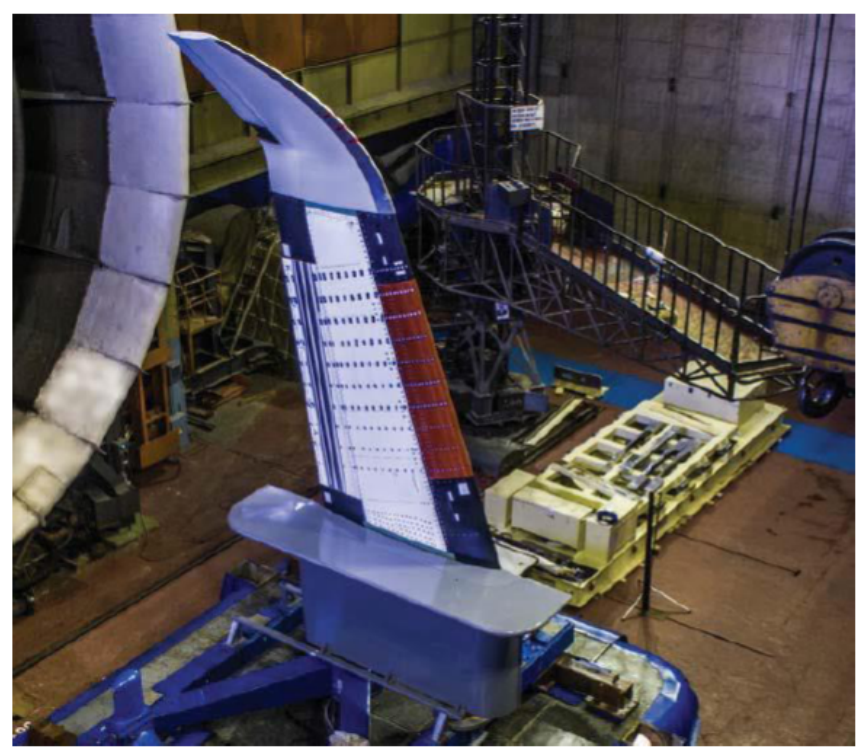

Figure 2: SARISTU Morphing Wing demonstrator installed in the T-104 wind tunnel facility at TsAGI (RUS), [5].

In the NASA-AFRL Adaptive Compliant Trailing Edge project, a flying prototype of an adaptive flap built by Flexsys was fully integrated in the wing-body, attaining something like 45-deg deflection without any discontinuity in the camber curvature (in other words, a continuous deformation was achieved). A variable camber wing was realized by deforming the trailing edge by means of electrical servomotors inside the flap to increase aircraft aerodynamic performance and perform load control and alleviation functions. A flight test campaign was carried out to demonstrate the airworthiness of the developed structural concept, conceived to replace the conventional Fowler flap on a NASA subsonic research aircraft testbed derived from a Gulfstream G-III, Figure 3, [8].

Currently, morphing wing devices are being developed in the framework of the ongoing research Airgreen 2, [9], a European Clean Sky 2 (CS2) project aiming at developing selected innovative technologies for the next-generation regional aircraft. Such models are planned to undergo both large wind tunnel and flight test campaigns in 2022-2023. In that case, a morphing winglet and an adaptive high-lift system, consisting in turn of a morphing droop nose and a morphing flap, are being developed by CIRA, the Politecnico of Milano, and the University of Naples, respectively. The first one incorporates a dedicated actuation mechanism driven by linear electromechanical actuators to adaptively control two independent finger-like adaptive surfaces enabling load control and alleviation functions, [10]. The second one proved to significantly increase the high lift performance of the natural laminar flow wing equipped with such deformable components, [11]. In detail, the morphing flap system is an evolution of what was realized in the previous years, [4]. Herein the movement is enabled by inner moveable articulations, shown in Figure 4, consisting of rigid blocks that are allowed to rotate in relation to each other to change the wing camber. The optimization process of such a 


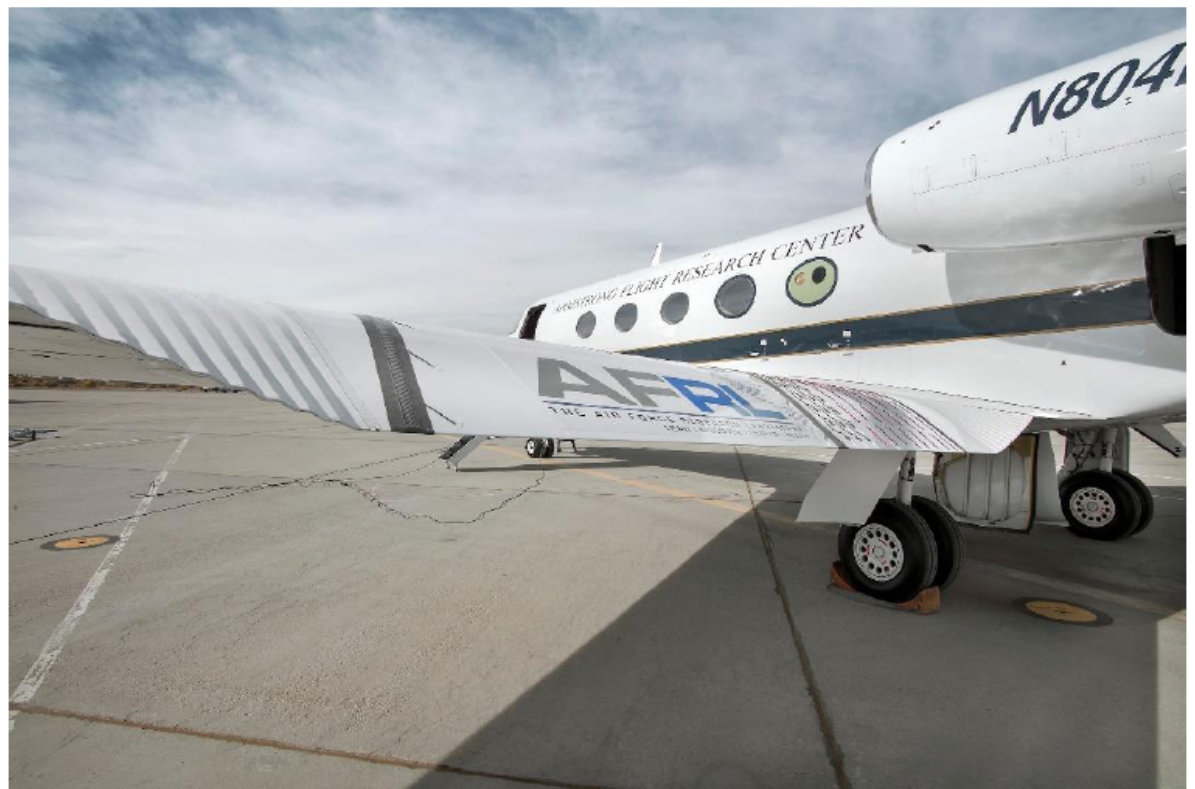

Figure 3: NASA, AFRL, FlexSys Adaptive Compliant Trailing Edge on the NASA Gulfstream G-III Aircraft, [8], Image credit: NASA.

complex device involves parametric kinematic analyses considering leverage components' number, shape, and position as functions of the mechanical advantage to be achieved by the overall mechanism, [12].

\section{ROBOTIC SYSTEMS}

Robotics may be seen somehow related to adaptive structures. In that case, the problem is approached from "another perspective". Rigorously, a robot is any machine that serves heavy work, replacing the need of human strength. A washing machine, a simple pallet truck are examples of robots. In the collective imaginary, however, the word robot has been more and more associated with something that tries to replicate the behavior and operation of a human, while the other systems are indicated with the generic term of machines, more brutally and perhaps efficiently. Thus,

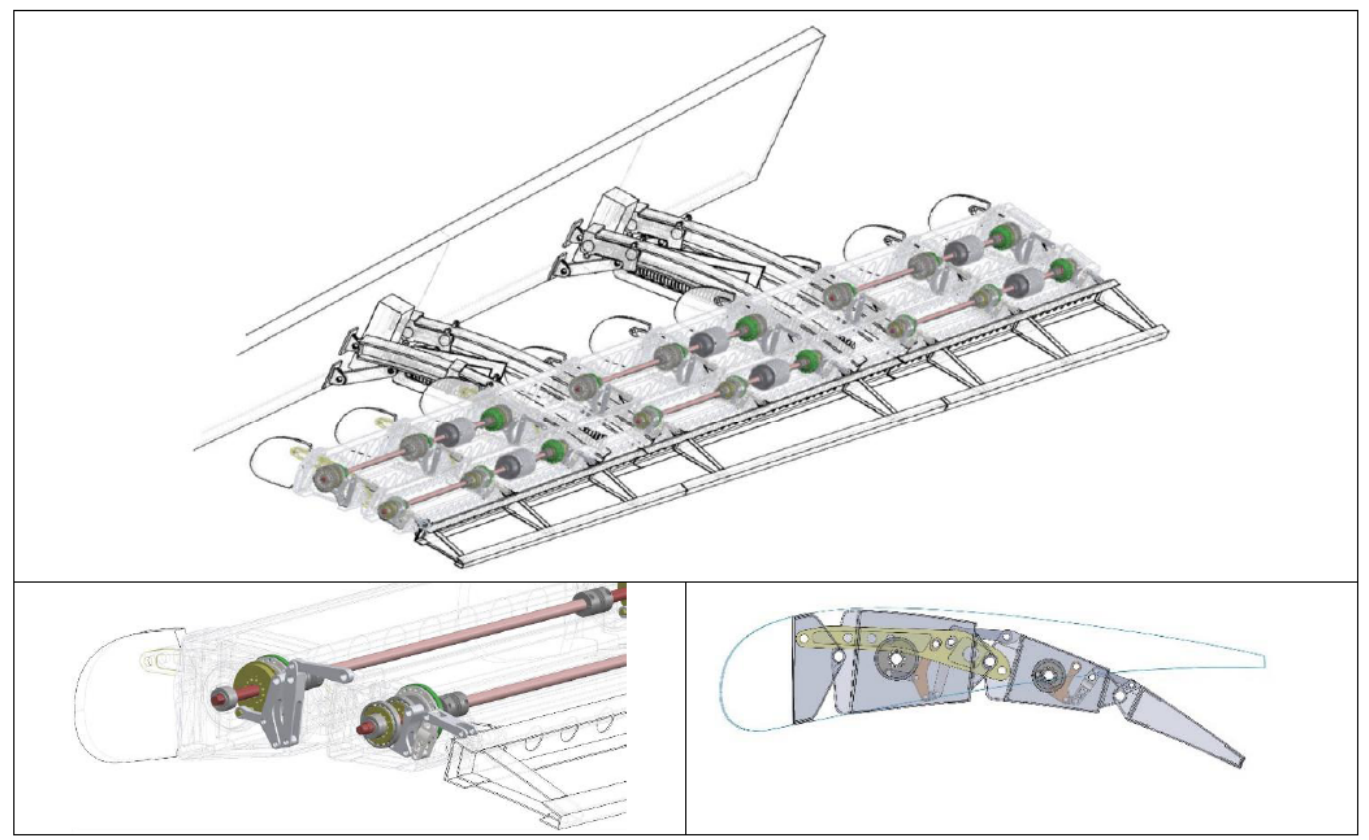

Figure 4: Multibody morphing flap developed in CS2 Airgreen2 project. 
when a robot is introduced, it is often a mechanical system that imitates the characteristics of a man or a woman, to some extent. More in general, a robot is also associated to something that replicates a living creature as a dog, a cat, or even an insect. Biomimetic robots have then completely assimilated the meaning of the word robot, almost for antonomasia. The step forward that this technology has moved in the recent years are impressive. There do exist robot able to play soccer, [13], to shoot with extreme precision, [14], to bring delicate substances from a place to another, [15], and even to operate autonomously, almost or completely. That latter aspect is, however, part of other subjects and is herein left apart. A certain focus of the research on robots, in a sense now described, is associated to the need of moving in perfect equilibrium, avoiding falls or even uncertain steps, or to the capability of handling things with extreme care, without hurting or damaging them, and so on. In other words, the emphasis of the research on robots as "mechanical systems" is "to be precise" in the most extensive sense of that statement.

Generally, it is possible to state that there is no special focus on the force that shall be exerted to resist external loads, or applied to an external object. Indeed, the study effort is spent to control it at the minimum as in the case of manipulating eggs or delicate surgery tools, [16]. The robot structure itself is not thought as something that can be deformable: it can be described as a set of rigid parts (multibody system). If increasing weight had not a direct impact on the actuators' power, and then on their size, it would be also correct to assert that weight is not an issue for that kind of machines. Among many outstanding projects that can be found in literature, some are reported as good examples of what stated until now. Supported by the European Research Council (ERC), the SOFTHANDS team did succeed in creating a hand robot that matched the ability to move and to apply different levels of strength, [17]. HoloBuilder, a software house specialized in products for supporting civil constructor operations, and Boston Dynamics, a robotics firm, released a dog-like robot (SPOT) to catch regular comprehensive overviews of ongoing activities, and to monitor and report real-time variations on the scheduled path, [18]. Potentialities of that same robot system have also been experimented by the Massachusetts State Police.

\section{DISCUSSION AND FUTURE PERSPECTIVES}

Standing that background, and hazarding a futuristic vision along the route tracked by many movies on the matter, it is easy to imagine how the developments of adaptive structures and robotics could meet at some point. Realization of robots able to change their shape as a function of their mission, strong enough to resist significant loads while being able to handle things with extreme precision, sufficiently accurate to substitute human hands operation in microscopic surgery, reliable enough to carry on human activities in planetary exploration, is something that is perfectly imaginable at this point of the research activities and their next evolutions, Figure 5, [19, 20].

There is no need to have some particular capability or sensitiveness for looking towards the times ahead. Maybe romantic perspectives, presented by movies like Transformers, [21], or Terminator [22], will never come to reality, but the essence of the prospected mental picture is exactly that. Making a further step ahead or aside, it can also be envisaged how robotic parts could
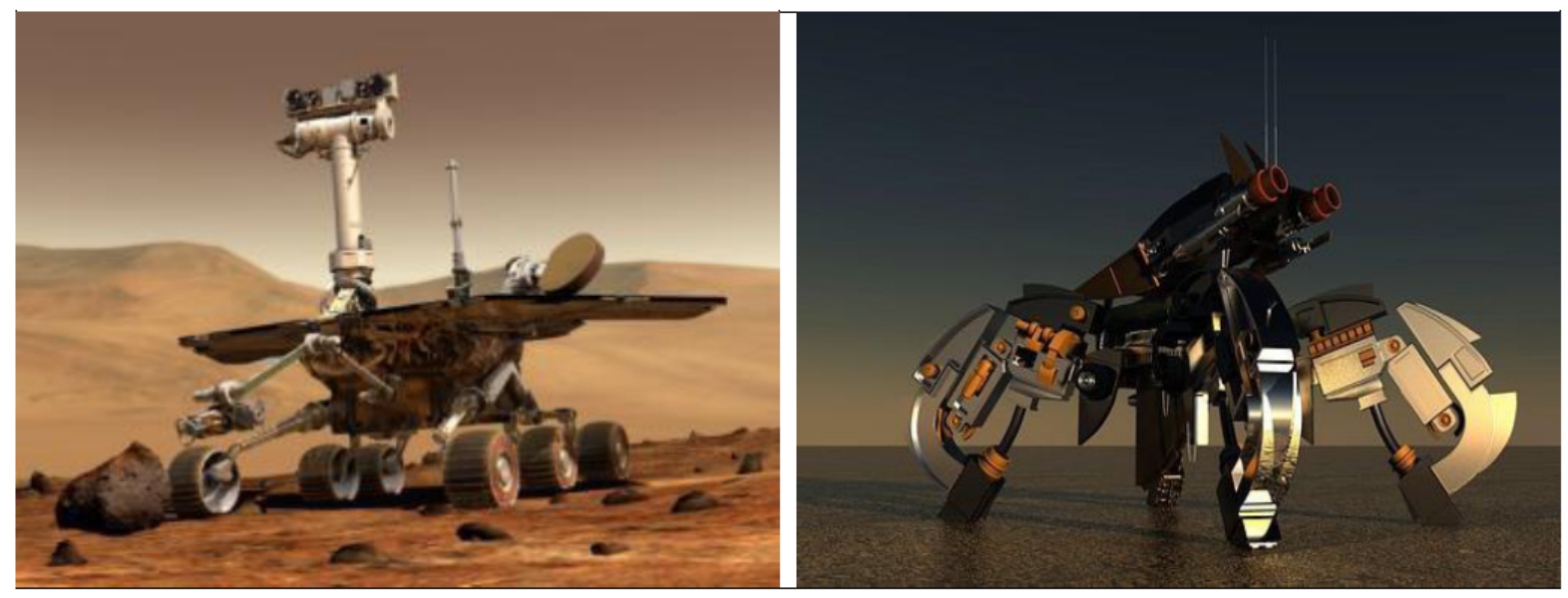

Figure 5: Robot for planetary exploration (left), [19], Image Credit: NASA/JPL/Cornell University; Flying/walking robot concept (right), [20], Image credit: Pixabay. 


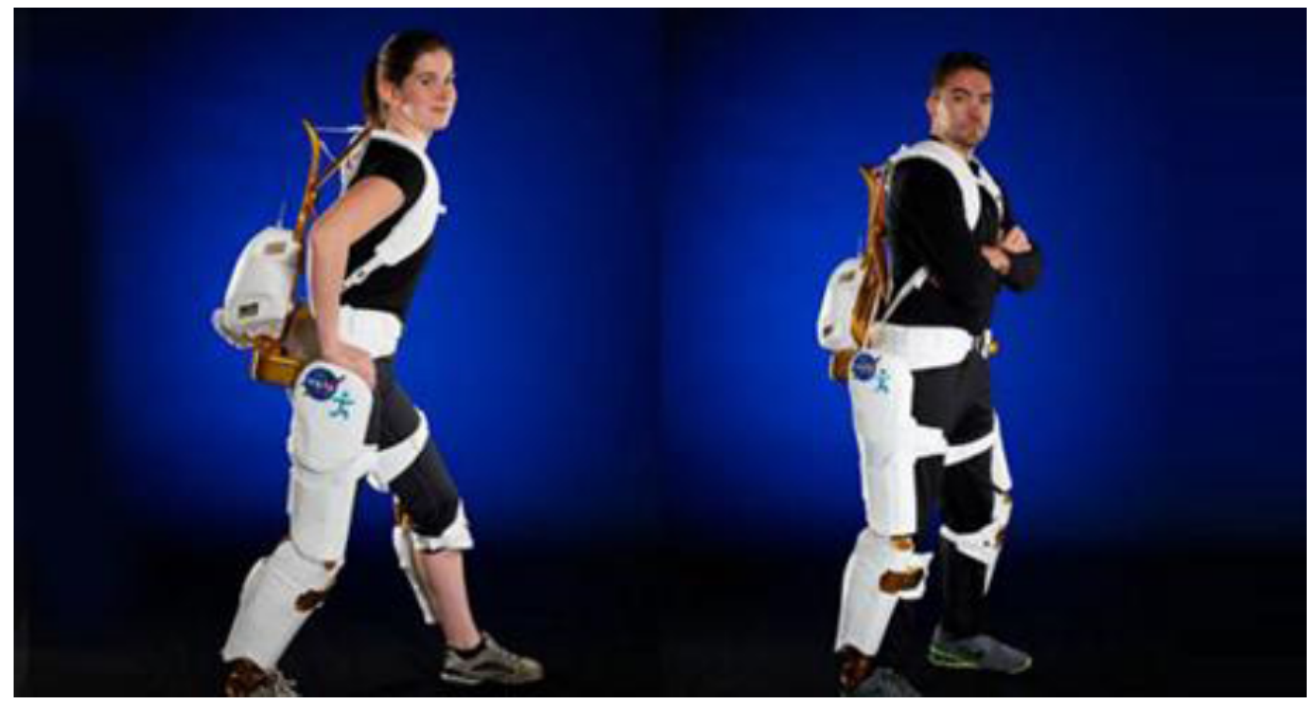

Figure 6: Exoskeleton concept proposed by NASA for facilitating space operations, [23], Image credit: NASA.

be integrated into a human body to help people with disabilities in overcoming their difficulties or handicaps, even partially. Exoskeletons as the ones proposed by NASA, Figure 6, [23], are the first examples of this further possibility that brilliantly avoid facing problems related to the direct incorporation of mechanical systems on a person (cyborg). Some of those are classical mechanic issues, as for instance, the need to ensure a perfect fitting with the bones while controlling tensions and strains transmitted to the coupling interface. Others regard extremely complex biomedical aspects as the connection to sensitive terminals and information pathways (nerves) to the machine and viceversa, in the way shown in Star Wars Episode V, [24.]. If someone should express concerns about the real possibility that cyborgs will be present in the far future, it could be answered that many of us are perhaps already those ones, [25, 26].

Today, people are so combined with their connection means (PC, tablet, smartphones, and so on) that these latter may be already considered parts of their body. And if the issue should be those devices are not physically linked, the obvious answer that in turn is a rhetoric question, would be "for how long?". Wearing a chip under the skin is definitely possible (our dogs already have it), and implementing voice commands is a diffused technology. Studies are ongoing for catching the brainwaves and using them to drive easy tasks of certain apparatuses, [27]. A kind of mind transmission via electromagnetic waves (enhanced phone calls) is not that far... It maybe these latter items move this speech too away from the original intentions, having started dealing with cybernetics, either. Coming back to the aforesaid perspectives, robotics, mechatronics, and adaptive structures science seem to be converging in the short-medium term, with some expected and many unexpected consequences on biomedicals, bioengineering, and biotechnology.

\section{REFERANCES}

[1] Morphing Wing Technologies: Large Commercial Aircraft and Civil Helicopters, Concilio A, Dimino I, Lecce L, Pecora R. (ed.), ISBN 9780081009697, Publisher: Elsevier Science, 2017.

[2] Smart Intelligent Aircraft Structures (SARISTU): Proceedings of the Final Project Conference, Woelcken P. C. Papadopoulos M. (ed.\}, ISBN 9783319224138, Publisher: Springer International Publishing, 2015.

[3] Morphing Aerospace Vehicles and Structures, Valasek J., ISBN 9781119940302, Aerospace Series, Publisher: Wiley, 2012.

[4] Pecora R. Morphing wing flaps for large civil aircraft: Evolution of a smart technology across the Clean Sky program, Chinese Journal of Aeronautics, 2021; 34(7): 1328, ISSN 1000-9361. https://doi.org/10.1016/j.cja.2020.08.004

[5] Riemenschneider J, Misol M, Schmidt D. (2016). Smart Structures: Recent Developments within Aeronautics Applications (Invited Review). Actuator 2016, Bremen, Germany, 2016; 13-15.

[6] Kuzmina S, Ishmuratov $\mathrm{F}$, Zichenkov $\mathrm{M}$, et al. Wind tunnel testing of adaptive wing structures. In: Concilio A, Dimino I, Lecce L, Pecora R, ed. Morphing wing technologies. Oxford: Butterworth-Heinemann; 2017; p. 713-55.

[7] Cumming SB, Smith MS, Ali AN, et al. Aerodynamic FlightTest Results for the Adaptive Compliant Trailing Edge. AIAA Atmospheric Flight Mechanics Conference, AIAA-2016-3855, June 2016.

https://doi.org/10.2514/6.2016-3855

[8] NASA. Harrington JD, Merlin P, Mayer D, Hill R. NASA Tests Revolutionary Shape Changing Aircraft Flap for the First Time. Nov 7th, 2014, Release 14-308. https://www.nasa.gov/press/2014/november/nasa-testsrevolutionary-shape-changing-aircraft-flap-for-the-first-time, 
Last Updated: Aug 7th, 2017, Allard Beutel ed. Last access April 2nd, 2021.

[9] Ameduri S, Concilio A, Dimino I, Pecora R, Ricci S. AIRGREEN2-Clean Sky 2 programme: Adaptive wing technology maturation, challenges and perspectives. In Proceedings of the ASME conference on smart materials, adaptive structures and intelligent systems, San Antonio, TX, USA, 10-12 September 2018, paper no. SMASIS2018-8235. New York: ASME.

https://doi.org/10.1115/SMASIS2018-8235

[10] Dimino I, Andreutti G, Moens F, Fonte F, Pecora R, Concilio A. Integrated Design of a Morphing Winglet for Active Load Control and Alleviation of Turboprop Regional Aircraft. Appl. Sci. 2021; 11: 2439 . https://doi.org/10.3390/app11052439

[11] Moens F. Augmented Aircraft Performance with the Use of Morphing Technology for a Turboprop Regional Aircraft Wing. Biomimetics 2019; 4: 64. https://doi.org/10.3390/biomimetics4030064

[12] Rea F, Amoroso F, Pecora R, et al. Structural design of a multifunctional morphing fowler flap for a twin-prop regional aircraft. Proceedings of SMASIS 2018 - Smart Materials, Adaptive Structures and Intelligent Systems Conference (San Antonio - TX, USA), sponsored by ASME (American Society of Mechanical Engineering), September 2018, Paper ID: SMASIS2018-7937. https://doi.org/10.1115/SMASIS2018-7937

[13] Dan X, Junhao X, Huimin L, et al. The design of an intelligent soccer-playing robot, 2016; 43: pp. 91-102. Industrial Robot: An International Journal. https://doi.org/10.1108/IR-05-2015-0092

[14] Lindner C. Skip the New Terminator, and Watch This Unnerving Robo-Apocalypse Instead, This is how the robots will take over, 2019, Popular Mechanics, https://www.popularmechanics.com/technology/robots/a2961 0393/robot-soldier-boston-dynamics/, last accessed Jan 1st, 2020.

[15] Ashish S, Amanpreet S. Kinematic Modeling of Robotic Manipulators, Proceedings of the National Academy of Sciences, India - Section A. 2016; 87: pp. 303-319 https://doi.org/10.1007/s40010-016-0285-x

[16] Su H, Yang C, Ferrigno G, De Momi E. Improved HumanRobot Collaborative Control of Redundant Robot for Teleoperated Minimally Invasive Surgery, IEEE Robotics and Automation. 2019; 4(2): pp. 1447-1453. https://doi.org/10.1109/LRA.2019.2897145

[17] Piazza C, Catalano MG, Godfrey SB, et al. The Soft Hand Pro-H: A Hybrid Body-Controlled, Electrically Powered Hand Prosthesis for Daily Living and Working, IEEE Robotics \&
Automation Magazine 2017; 24(4): 87-101. https://doi.org/10.1109/MRA.2017.2751662

[18] Zeiba D. Roaming robot dogs could streamline jobsite documentation, 2019, The Architect Newspaper, https://archpaper.com/2019/12/roaming-robot-dogs-spotstreamline-jobsite-documentation/, last accessed Dec 30th, 2019.

[19] NASA JPL. Artist's Concept of Rover on Mars, https://photojournal.jpl.nasa.gov/catalog/PIA04413. Last updated: Feb 26th, 2006, last access, April 3rd, 2021.

[20] Pixabay. Futuristic robotic concept, https://pixabay.com/illustrations/robot-monster-ufoelectronics-2116088/. Published, March 5th, 2017, Latest access, April 2nd, 2021.

[21] The Transformers: The Movie, Director: Nelson Shin, Production company; Sunbow Productions, Marvel Productions, Toei Animation: Produced by; Joe Bacal, Tom Griffith, Edited by; David Hankins, Music by; Vince Di Cola, 1986.

[22] Terminator 2, Director: James Cameron, Production company; Carolco Pictures, Pacific Western Productions, Lightstorm Entertainment, Le Studio Canal+ S.A., Produced by; James Cameron, Edited by; Conrad Buff, Mark Goldblatt, Richard A. Harris, Music by; Brad Fiedel.

[23] NASA. Hall L. NASA's Ironman-Like Exoskeleton Could Give Astronauts, Paraplegics Improved Mobility and Strength, First Publ., Aug 2, 2013, https://www.nasa.gov/sites/default/files/images/724154main exoskeleton 466.jpg. Last updated: Aug 7th, 2017, last access: Apr 2nd, 2021.

[24] Star Wars, Episode V, Director: Irvin Kershner, Production company; Lucasfilm Ltd., Produced by: ‘Gary Kurtz, Edited by: ¡Paul Hirsch, Screenplay by; Leigh Brackett; Lawrence Kasdan, Music by: John Williams.

[25] Pohl R. Donna Haraway's A Cyborg Manifesto, ISBN 9780429818714, series The Macat Library, 2019, Publisher: Macat Library.

[26] Haraway DJ, Wolfe C. Manifestly Haraway, ISBN 9781452950136, series Posthumanities, 2016, Publisher: University of Minnesota Press. https://doi.org/10.5749/minnesota/9780816650477.001.0001

[27] Al-Quraishi M, Elamvazuthi I, Asmah Daud S, et al. EEGBased Control for Upper and Lower Limb Exoskeletons and Prostheses: A Systematic Review, 2018; 18: pp. 27, Sensors. https://doi.org/10.3390/s18103342

(c) 2020 Concilio et al.; Licensee Zeal Press.

This is an open access article licensed under the terms of the Creative Commons Attribution Non-Commercial License (http://creativecommons.org/licenses/by-nc/3.0/), which permits unrestricted, non-commercial use, distribution and reproduction in any medium, provided the work is properly cited. 